\title{
Rapid Prototyping of Interactive Storytelling and Mobile Augmented Reality Applications for Learning and Entertainment - The Case of "k-Knights"
}

\author{
http://dx.doi.org/10.3991/ijep.v6i2.5560 \\ D. Markouzis, G. Fessakis \\ University of the Aegean, Rhodes, Greece
}

\begin{abstract}
Mobile Augmented Reality (MAR) Technology in combination with Interactive Storytelling (IS) enables the design of new kinds of technology enhanced learning and entertainment applications. The existing pedagogical research as well as the available Interactive Storytelling MAR (ISMAR) Serious Games are rather limited. This is mainly because of the difficulties of MAR applications development and the complexity of IS authoring. The paper works on the direction to improve this situation exploring the combination of a) rapid prototype development methodology based on MAR authoring tools and $b$ ) the definition of IS genres which could serve as templates and guide the ISMAR design. In the paper, key concepts are presented, existing successful examples of MAR Serious Games are analyzed in order to extract their narration genre features, available tools for MAR rapid authoring are introduced, and afterwards the design, development and first evaluation of a prototype ISMAR Serious Game is presented. The paper contributes to the bridging of learning design, IS, and AR technology research communities and facilitates feature interdisciplinary research.
\end{abstract}

Index Terms-Augmented Reality, Interactive Storytelling, Mobile Learning, Serious Games

\section{INTRODUCTION}

Mobile devices with considerable computing power such as smartphones, tablet PCs and iPads are becoming more and more widespread and accessible [16]. In addition, Mobile Augmented Reality (MAR) technology matures, making feasible new kinds of applications with great potential for learning and entertainment. MAR apps take advantage of the awareness of time, position, and user state context for digital interaction with the environment [13], [18], [19]. This kind of applications dynamically overlay digital information on the natural environment, enhancing the interaction with space, natural or structured. MAR technology does not only concern the information delivery and other utilitarian applications but it also affects learning (formal and informal) and recreation activities for students, residents and visitors of certain locations. These applications could be described as a special kind of serious games, namely location depended MAR serious games [18]. Serious games are one of the most popular choices for spending free time [4]. MAR technology has great potential in education and entertainment applications [13]. MAR serious games are obviously consistent with the situated learning theory [20] which advocates that learning is more effective through collaborative authentic problem solving, in the natural environment where the constructed knowledge is used. In addition, according to [3], MAR learning applications can also support the mixture of modern student centered pedagogical approaches including: a) constructivist learning, b) situated learning, c) game based learning and d) inquiry-based learning for the creation of rich and optimal authentic, and contextualized learning experiences. These experiences in turn help the students form their own learning paths, engage, immerse and interact meaningfully via digital narratives and virtual role identities.

In parallel, Interactive Storytelling (IS) [27] [5] is gaining increasing attention by Humanities Informatics, Digital Games Based Learning and Information and Communication Technology (ICT) research communities. This is mainly because the location dependence and context awareness of the MAR technologies facilitates new kinds of IS applications [23]. Interactive Storytelling MAR (ISMAR) applications are complex and demanding interdisciplinary projects which need the collaboration of humanities and technology experts. This paper focuses on ISMAR Serious Games, aiming to facilitate their learning design and research while exploring the feasibility of the rapid prototype methodology for ISMAR design and development.

In the paper, firstly, Interactive Storytelling and its relation to learning is briefly introduced, then a short introduction of Mobile Augmented Reality is made, followed by successful examples of MAR Serious Games which are reviewed and their design features are analyzed. Subsequently, MAR development technology is explored and available rapid authoring tools are presented, which are required for the rapid prototype methodology to be feasible. Thereafter, the design of an ISMAR Serious Game prototype named "Rhodes K-nights" is described. The game serves as an evidence of rapid prototyping feasibility for ISMAR learning applications as well as an illustration of the use of narrative genres for the guidance of successful mobile interactive storytelling design for learning. "Rhodes K-nights" will serve as a case study for learning designers training and future research. Game analysis is followed by the description of experimental evaluation of the pilot game by seven college students of the University of the Aegean. The paper ends with summary and discussion.

The paper aims to facilitate the bridging of the learning design community with the mobile augmented reality 
learning and interactive storytelling ones, in order to extend the ISMAR learning applications and research. To achieve this goal, the authors study the combination of low threshold and high ceiling MAR development technology with effective methodology of ISMAR learning design, based on well-defined genres of narration and sound pedagogical approaches.

\section{INTERACTIVE STORYTELLING AND LEARNING}

Story structures (sequences of events connected with cause and effect relationships) are considered fundamental building block of human mechanism for making meaning out of experience [1][2]. As a consequence, stories creation and understanding are significant epistemological tools for humans' effort to organize their knowledge and make sense of their subjective reality, their self-concept, and the social environment. Bruner [1] distinguishes two modes of thought for the interpretation and understanding of the world and the social experiences. The first one, called the paradigmatic mode, is the scientific method for the logical categorization of the world. The second one, called the narrative mode, concerns the use of stories to make meaning of experiences. More specifically as Bruner [1] says: "the paradigmatic or logical-scientific one, attempts to fulfill the ideal of a formal, mathematical system of description and explanation. It employs categorization or conceptualization and the operations by which categories are established, instantiated, idealized, and related to one another to form a system." (p. 12). The narrative mode, as Bruner [1] explains, concerns stories about "human or humanlike intention and action and the vicissitudes and consequences that mark their course" (p. 13). Thus, stories store the personal explanations of the complex world of human intensions and their planning to achieve them. The two modes of thought are complementary and none of them can be reduced to the other. The significance of storytelling in teaching and learning is well known [9] [17].

Applebee [34] advocates that the children enjoy and understand abstract and imaginary stories from their early age. This finding increases the scientific interest about understanding and creation of stories as an epistemological tool and learning method. The integration of a problem into a story structure helps student to address it successfully. This observation narrows the scope of applicability for widespread common beliefs about the cognitive development and the learning ability of the children. More specifically Egan mentions the contradictory results on the Piaget's and Inhelder's "three mountains experiment", which examined spatial ability of children, from Martin Hughes, who implemented an equivalent experiment integrating the problem/task of the previous research into a story. Egan [9] believes that the construction of appropriate stories can be an alternative way of learning design. Recently, there is an increasing interest for digital storytelling, in the ICT enhanced learning research community [24] [27] [28]. Furthermore, interactive stories enable the reader/player to participate and affect the plot of the story, offering new types of narrations, more engaging and adaptive. Many researchers believe that digital interactive storytelling has the potential to become a premier art form of the 21 st century but it is still in an infant stage of development [27]. Conventional stories present a static sequence of events connected by an also static chain of cause-effect relationship (plot). In contrast, interactive stories present a dynamic sequence of events and a nonlinear plot which is determined during the "reading" of the story according to the user's actions and choices. The end of the story is not predetermined by the author and the story usually emerges during the narrative [5]. There are levels of interactivity for stories, from simple branching stories to fully dynamic plots based on sophisticated Artificial Intelligence techniques and narration models, e.g. the case of Façade [22]. The reading and the authoring of high quality interactive stories rise difficulties concerning their development but also their design methodology, since it is a high complexity and creative activity which varies significantly in comparison to traditional text composition [29]. More specifically, the design of educational interactive stories, demands the combination of writing and learning design capabilities. Furthermore the design of interactive storytelling for computer games faces even more complexities and concentrates the interest of many researchers and practitioners because of its significance in the modern digital media world [12]. The educational research concerning the interactive storytelling role in teaching and learning is fairly in its first steps. Interactive stories "reading" should not be considered an easy task since it is similar to hypertext reading and as [32] mentions, reader often become confused and disoriented. Furthermore the research shows that the composition of interactive hypermedia requires and simultaneously promotes high-level thinking [31]. Reference [30] mentions some preliminary positive results for the learning value of IS and proposes directions for future research including: $a$ ) Interaction and technology concerning the impact of new technologies and interaction paradigms e.g. the exploration of MAR technology impact to IS, b) Innovative narrative genres concerning the relation of narrative genre (e.g. quest, adventure game, etc.) to the learning efficiency of IS c) Context, impact and evaluation concerning the research about which context (e.g. school, outdoor etc.) is effective for IS based learning, how this effectiveness could be evaluated and how IS could be embedded efficiently and sustainably in education.

\section{Mobile Augmented Reality - New Way OF MOBILE LEARNING}

In parallel with the increasing interest for digital storytelling, a new genre of learning arises, the mobile learning (m-learning). The [35] states that in a survey of Educause Center Applied Research about Mobile IT in higher education, $67 \%$ of surveyed students use their mobile devices for academic activities, like access to educational content or interaction with their instructors and their colleagues. Moreover many researchers [35] argue that mobile learning is appropriate for both formal and informal learning. Mobile devices allow users to learn everywhere and anytime. The learning process goes along over the classroom and the house and takes place in most unlikely places like subway stations and public squares. Sandberg [36] believes that the current research in m-learning is affected by two major facts. The first one is the growing belief that the informal learning is as important as formal and the second one is the emerging technological capabilities such us location detection, internet access and multimedia presentation. These are some of the basic features that exploit augmented reality to dynamically overlay digital information on the natural environment, enhancing the interaction with urban, natural or structured space. Many re- 
searchers have tried to define the term AR [33], [37], [38]. The authors form into Klopfer's opinion [18], who argues that it is difficult to define exactly AR due to the fact that any definition could restrict the exact meaning. Any technology that combines real and digital information in meaningful way can be considered AR. In our case, our basic interest lays on mobile device applications and how they can be used in order to exploit the AR advantages for learning and entertainment purposes. The authors refer to these applications as MAR Applications. There are two basic categories of such technology: 1) Location based augmented reality based on GPS technology, which delivers digital information to user according to his/her real location, and 2)Vision based augmented reality, which demonstrates digital information recognizing real objects or QR codes which the user shoots through the camera of his/her mobile device.

Serious games for mobile devices can be combined with MAR technology providing new opportunities for entertainment and learning [33], [14]. Mobile technology allows the designers to include real places into the story fiction increasing the authenticity of the game and emerging the engagement of the players. The users have to collaborate or anticipate each other according to her/his role, visit real locations and collect virtual and real objects in order to solve the puzzles. Also, by overlaying digital content on real objects and places, the players can understand better scientific phenomena and connect them with real time situations, perceive the flow of dynamic systems, learn the history and culture of place and become more sensitive about environmental problems than in real classroom.

However, the cognitive demands and the difficulties of ISMAR Games design for learning need more research to be done in a depth that will permit their use by learning designers. Currently, the existing educational applications are rather very few in number [7]. The development of user friendly authoring tools for MAR Serious Games could help to increase the experimentation with the ISMAR design and development and could promote its understanding and pedagogical research. In addition, thorough analysis of existing successful applications is considered useful for better understanding of the craft along with recognition of design heuristics, patterns and best practices. As a result, this could help to describe general genres of interactive storytelling serious games which could be used as models or guidelines to increase the development of applications by educators, learning designers and writers. Such genres include: quests, adventure games, mystery games, treasure hunts, scavenger hunts, races, real world simulations, role playing games, time travels and journalistic games. In the following section, some well-known examples of MAR Serious Games are reviewed under this goal view. The aim of the authors is to find and/or develop exemplars of ISMAR learning applications for each genre, using rapid authoring tools in order to be able to familiarize e-learning designers with ISMAR applications design and development and to facilitate the educational research about the ISMAR relation to learning.

\section{CRITICAl REVIEW OF Existing APPLICATIONS}

Since there are a few MAR Serious Games applications available and most of them are not designed as IS applications, despite the fact that include narration, we choose some well-known, documented in research and generally considered successful examples apps in order to review their Interactive Storytelling features. More specifically, except the general concept we are interested in the narration genre of the application, the subject of the learning goals, the research results about the application, and the technology used for the development.

\section{A. Mentira}

"Mentira" (http://www.mentira.org/) [14] is an example of location-based augmented reality game for Albuquerque city. Mentira combines narration, real facts, visual characters and real people. The purpose of the game is learning Spanish as a foreign language. According to the story, the players must solve a murder in Los Griegos, a Spanish-speaking neighborhood in Albuquerque, in USA. Not all the players have the same role in the game. According to his/her role, each player receives different information in the game. In order to solve the mystery the players have to interview fictional characters and to collect evidence from real places. The evidence is superimposed as digital information in the game location. Every player creates his own learning path in the story and collaborates with his teammates exchanging evidence to find the murderer. The findings of the game experimental study revealed that the most players showed increased interested about the place where the game takes place and about the participation in creating an extension of the game. The narration of the game is obviously a mystery; the game is collaborative using the "jigsaw" collaborative learning script [39]. The application has been implemented using special ARIS authoring tool.

\section{B. Alien Contact}

"Alien Contact" [6] is also a location based AR mystery game. The players try to solve a mystery about an alien spaceship which crashed just outside their classroom. Each player has his own role (chemist, cryptologist, computer hacker and FBI agent) in a team of four. Using a Dell mobile device with GPS they walked around the school field to gather evidence by interviewing virtual characters, collecting items and solving mathematical puzzles in order to find the solution. According to the research findings, the players enjoyed the use of new technologies such as smartphones and tablets, the opportunity that a school activity happened outside the classroom and the ability to collaborate with each other to collect data and exchange information due to their different roles. The role existence and the fictional narrative of the game have as result to activate a sense of a projective identity to players which increased the engagement and the immersion during the game [11]. Alien contact is characterized as AR Simulation by its designers and has been developed using professional AR development software rather than an authoring tool. The story of the application is again a mystery game. The application covers specific math and language learning standards.

\section{Mad City Mystery}

"Mad City Mystery" [26] was used to support learning in environmental science. The goal of the game is to investigate the cause of death of Ivan in University of Wisconsin-Madison near Lake Mendota. In order to do so, the players chose one of three roles (medical doctor, environmental specialist and government official) and investigated the area by visiting real and digital places, interviewing 
digital characters and using virtual objects like digital newspapers etc. Depending on the role, different information is showed to the player. This implies that the participants have to collaborate, using a jigsaw collaboration script [39] to overcome the challenges of the game. It was strongly believed that the roles encouraged collaboration and that the place and narration engaged students in authentic situations and helped them to transfer abstract scientific concepts into real life situations. The narration genre of the game is a mystery. The story is rather static but the users may experience different narrations according to their choice of the sequence of places visited and agents interviewed.

\section{D.Outbreak@theInstitute}

The game "Outbreak @ the Institute" [25] was played across a university campus where the players were trying to identify the source of an infectious disease and protect the virtual citizens from getting inflected. The players joined the game choosing among three different roles with different abilities which were Medical Doctors, Field Technicians and Public Health Officials. They interacted with virtual and real characters, made virtual diagnostic tests and administered medicines. The game used a probabilistic model of disease transmission to increase plausibility. This means that players and virtual characters could inflect each other depending on game features which were invisible to players. There were not specific criteria of winning the game and instead of it, the players had to gather enough information and take the right decisions to limit the disease spreading in constrained time span. As a result, the progress of the game depended on players' decisions, which means the storyline was not the same for all the participants. The findings revealed that the different roles fostered the collaboration and the communication among the students and made the game environment more authentic to them. Furthermore, the use of real locations superimposed of virtual characters and the open-ended challenge of the game increased the authenticity. The narration genre of the game is also a mystery, such as in the three previous examples, but the plot has a branching structure giving a more interactive story.

\section{E. Frequency 1550}

The "Frequency 1550" is a city mobile game enabling the players to learn about the history of Amsterdam [15]. The players are separated in teams of four of five and randomly assigned the identity of beggar or merchant. Each role has different abilities in the game. The objective is to gain citizenship in the city of Amsterdam by collecting 366 points. The players visit specific locations in Amsterdam. At each location they have to complete some challenges. More over the teams could come in confrontation and the wining team wins points from the losing team. In confrontations the roles are important. The participants can also disable the screens of the mobile devices of the opponents by sending them medieval rats. The results revealed that the most students enjoyed the game and gained higher scores on the knowledge test about medieval Amsterdam in comparison with students who implemented usual project learning activities. The game has a quest narration with time travel characteristics based on historical events in the city of Amsterdam. The game has developed using professional mobile and AR application development tools. The plot of the game story is rather linear but the competition among the teams permits emerging storylines as far as the user experience is concerned.

\section{$F$. Ingress}

Ingress is a massively multiplayer role play city game which uses location-based augmented reality. It is created by Google's Niantic Labs and is played both in Android and iOS devices. In the game, two factions fight each other to gain the control of the planet. The players have to visit locations with high cultural significance which are represented on the map of their mobile phone trying to create virtual triangular fields. As conclusion, the players are encouraged to explore important places such us monuments and landmarks where they meet other teammates who are near to them. The narration genre of the game is rather a long term on-going race with on-going plot and a science fiction theme with learning goals much more thin than the entertainment ones. The game was developed using a custom mix of technologies and far from the idea of a simple authoring tool.

\section{G. Dow Day}

"Dow Day" is a prototype game created using ARIS authoring tool in which the player takes the role of a news reporter and tries to investigate the different perceptions of virtual characters who participated in protests against Dow Chemical Corporation for making napalm for the war in 1967. The application uses a journalistic narration genre.

Table I summarizes the main features of the reviewed games. Most games are based on the mystery narration genre which reveals as a quite popular plot model. The mystery structure is used in combination with collaborative inquiry pedagogical approach in which the jigsaw model of collaboration [39] is applied.

TABLE I.

SUMMARY OF THE ISMAR GAMES ANALYSIS

\begin{tabular}{|c|l|l|l|c|}
\hline & $\begin{array}{l}\text { Story genre and Struc- } \\
\text { ture }\end{array}$ & $\begin{array}{c}\text { Social } \\
\text { mode }\end{array}$ & \multicolumn{1}{|c|}{ Pedagogy } & Subject \\
\hline A & Mystery, static, fiction & $\begin{array}{l}\text { Small } \\
\text { group }\end{array}$ & $\begin{array}{l}\text { Collaborative } \\
\text { Inquiry }\end{array}$ & Spanish \\
\hline B & $\begin{array}{l}\text { Mystery, static, } \\
\text { science fiction }\end{array}$ & $\begin{array}{l}\text { Small } \\
\text { group }\end{array}$ & $\begin{array}{l}\text { Collaborative } \\
\text { Inquiry }\end{array}$ & Math's \\
\hline C & $\begin{array}{l}\text { Mystery, static, science } \\
\text { fiction }\end{array}$ & $\begin{array}{l}\text { Small } \\
\text { group }\end{array}$ & $\begin{array}{l}\text { Collaborative } \\
\text { Inquiry }\end{array}$ & Biology \\
\hline D & $\begin{array}{l}\text { Mystery, interactive, } \\
\text { science fiction }\end{array}$ & $\begin{array}{l}\text { Small } \\
\text { group }\end{array}$ & $\begin{array}{l}\text { Collaborative } \\
\text { Inquiry }\end{array}$ & Biology \\
\hline E & $\begin{array}{l}\text { Quest. static, history } \\
\text { based fiction }\end{array}$ & $\begin{array}{l}\text { Small } \\
\text { group }\end{array}$ & Inquiry & History \\
\hline F & $\begin{array}{l}\text { Race, emergent, } \\
\text { on- going plot }\end{array}$ & $\begin{array}{l}\text { MMORR } \\
\text { PG }\end{array}$ & Facts learning & $\begin{array}{c}\text { Entertain- } \\
\text { ment }\end{array}$ \\
\hline G & $\begin{array}{l}\text { Journalistic, static, } \\
\text { history based fiction }\end{array}$ & $\begin{array}{l}\text { Individu- } \\
\text { al }\end{array}$ & Inquiry learning & History \\
\hline
\end{tabular}

The users are "forced" to collaborate in order to solve the mystery because according to their role they have access to a separate part of the required information and/or competences. The narration seems non-linear to the player because he/she has the freedom to choose the sequence of "reading" the story parts but in reality it is quite static from the author's point of view, thus facilitating story authoring. The themes of the stories are often fictional, based on science or history. Small group social mode is more manageable and compatible than formal education environments. As far as the topics are concerned, the 
games show a great variety from math, science, language, history, geography and culture.

The review of the games gives evidence that the mystery narrative genre applied for fiction, in combination with the collaborative inquiry pedagogy, constitutes a popular and successful model for ISMAR Games design. A more systematic review will be implemented in the future to reveal more narration genres and IS design patterns. In addition, underrepresented narration genres will be used for the development of new ISMAR apps.

\section{RAPID AUTHORING TOOLS FOR ISMAR APPLICATIONS}

The development of AR applications has evolved impressively. The first AR applications development was very hard because it required the mastering of several complicated technologies. Those applications were mostly experimental, proof of the concept demonstrations and their implementation was difficult to manage in terms of cost and development time. The advances of the component technologies and the spreading of mobile computational devices contributed to the evolution of the MAR development and deployment models. In 2008 the first AR browser (wikitude) appears, marking the passage from the isolated applications development to the model of AR authoring for browsers. Soon, several browsers follow (e.g. Aurasma, Layar, Junaio and BuildARetc) along with the competition of leading companies (Google, Apple, IBM, Microsoft) for the dominance of the browsers popularity. AR browsers facilitate the AR applications development because they provide easy to use API's to the component technologies. The browsers provide also free access to royalty demanding technologies, making feasible the deployment of more applications. The authoring environments that accompany the browsers permit to users with lower technical background to develop quite complex MAR applications while at the same time they enable the rapid prototyping of more sophisticated ones [10]. Recently, authoring tools designed especially for the development of MAR serious games became available. For example ARIS and TaleBlazer are free authoring tools created by University of Wisconsin-Madison and MIT respectively. Both environments are user friendly, permitting rapid prototyping even by students. The conceptual model of ARIS seems to support more efficiently the Interactive Storytelling development since it provides abstract constructs like "scene", "dialogs" and "quest". The authors decided to develop a first prototype (which is described in the next section) using ARIS [21] because of its popularity and facilitation of the IS implementation. In the future, the same game will be developed using TaleBlazer in order to have a more thorough comparison among the two platforms.

\section{A CASE Of ISMAR RAPID PROTOTyPe DESIGN}

As follows from the existing successful analysis of games, the mystery narration genre is quite popular. A well designed mystery solving story seems an efficient way to engage students on task and make learning enjoyable, therefore this is a basic reason to choose it for our ISMAR game prototype. Mystery model in combination with inquiry pedagogical approach allows the player to a) collect and compare information from multiple and contrasting resources, b) exclude inferences by combining the

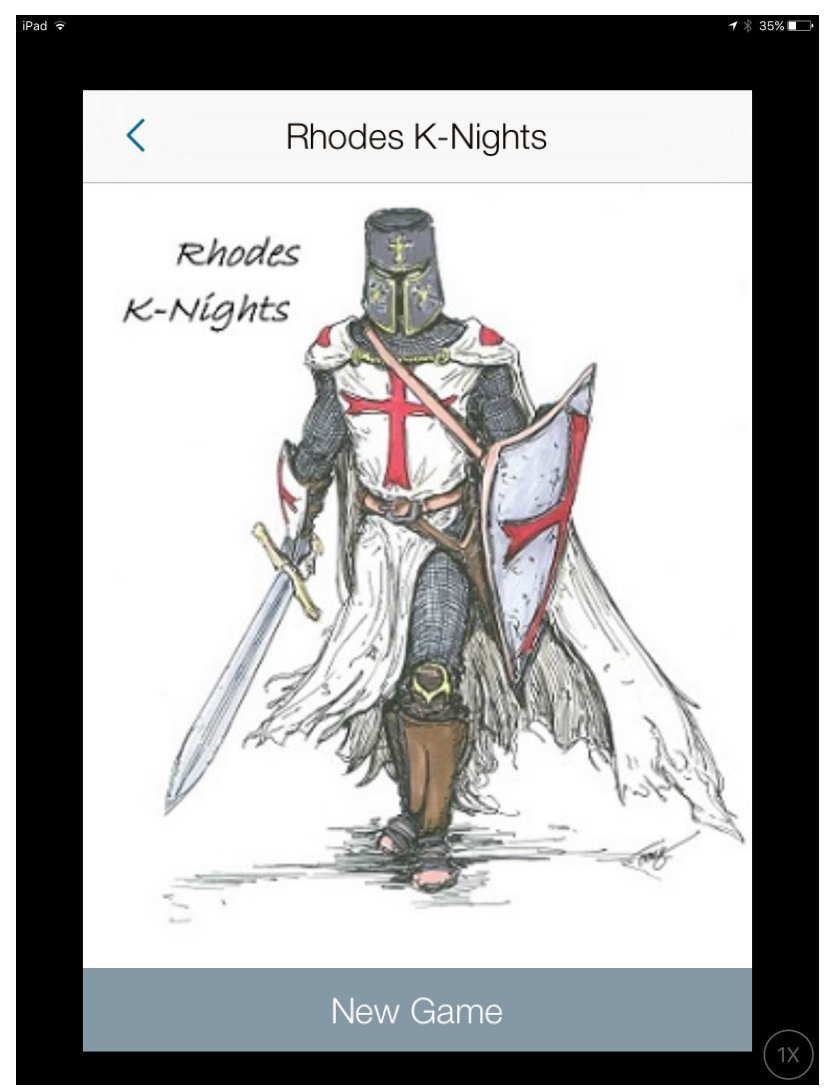

Figure 1. Welcome Screen of Rhodes K-nights

collected data and c) choose the best solution while rejecting the tricky ones in order to solve mystery puzzles.

The subject of our game, "Rhodes K-nights" (Figure 1), concerns the medieval history of Rhodes Island in Greece. Rhodes Island in the southeastern of the Aegean Sea in Greece has long history, dating back to 400 B.C. Because of the famous medieval city of Rhodes, which is cultural heritage of UNESCO, the medieval history of the island is gaining more interest for ISMAR games design. The purpose of our game is to introduce the player to this historic period of the city and to learn about the Knights' society, the palace and the Gothic and Renaissance architecture of the city.

According to the plot of the game, the player is a ghost hunter in our days who tries to catch a ghost of a knight who belonged in the Order of the Knights Hospitaliers of Saint John of Jerusalem who came to Rhodes in 1300 A.C. The ghost hunter is wandering inside the medieval city and the player collects data from scared virtual characters who admit that they have seen it. The player visits places in the city with cultural interest where the ghost was supposed to be and gathers information. At each location the player has to solve historical puzzles in order to move to the next challenge. The final scene of the game is in municipal garden of Rhodes where a special videoaudio theater performance without actors is performed. There he/she realizes that the ghost is actually a trick of a sneaky bad guy, special effect technician of the theater whose gang wants to frighten the locals and the tourists and depose the current mayor, in order to avenge his dismissal from the municipal theater. The current version of the game provides one quest, which is the ghost capture by the player. It also contains three basic scenes, according to ARIS authoring tool terminology. The first scene 
introduces the player to the story of the game. The second is the main scene in which the player hunts the ghost all over the medieval city. The third and final scene takes place outside the municipal garden where the player realizes the non-existence of the ghost and solves the mystery. "Rhodes K-nights" provides a single role for the player, that of a ghost hunter, but at the same time it has many agents, who are citizens of medieval city, shop keepers and tourists. Player interviews them to collect information and objects which are stored in his/her inventory. He/she also collects objects when he visits special locations like the palace or reads some plaques with important messages. Although the main part of the story takes place in the second scene, not all the objects and agents/characters appear at once from the beginning of the scene. The story unfolds gradually depending on the player's actions. For example, the player has to talk to the tourist who stands by the fountain in the central square of the medieval city before he/she becomes able to see the black mark which looks like a human body on the wall of the old city.

\section{EVAluation Research Design}

To evaluate our game, we conducted a case study on a small group of college students of University of the Aegean in Rhodes in order to compare the learning effects regarding the history of Medieval City of Rhodes and to estimate the level of engagement, motivation and collaboration of the students.

\section{A. Participants}

The participants of the experiment were seven students of University of the Aegean of Rhodes who accepted to play the game voluntarily. They made three groups of two students and one of them played the game alone. Each group played the game by themselves at different times and all the process was video-recorded.

\section{B. Method}

The game was played in Medieval City of Rhodes. Each group used their mobile phone in order to play the game. There was one device per group, except form the player who had no team. This forces the players to share the screen while following the flow of the game. For example, they share it to read the conversations with the visual characters or to see the items in inventory. The groups played the game at different times independently.

The researchers helped the students to download and install the game and ARIS application from Apple App Store at their mobile phones and gave them general instructions about the use of the app. Then each group played the game without any help. The walkabout of experimental groups in Medieval City were video-recorded.

\section{Data Collection}

The first tool of data collection was the videos that the researchers recorded during the play of the game. The second was a no name multiple choice learning test. This consisted of fifteen questions relevant to the story of the game and to the history of Medieval City of Rhodes. Each question had three possible answers from which only one was correct. The participants, in order to give the correct answer, had to remember information that was revealed from the conversations with virtual characters and from collection virtual objects while they were playing the game. The third was an anonymous questionnaire which consisted of thirty five, seven-point Likert scale questions. The answer for each question was an integer in the range one to seven. The number one corresponded to the most negative attitude and number seven to the most positive one. Finally, the fourth measurement tool was an interview which was conducted with all the students at the same time. During the interview, the participants were asked about the difficulties and the advantages of the game. Moreover, they proposed specific suggestions for the improvement of the game. Except of the multiple choice learning test which was used to measure the learning outcomes of the students about the history of the Medieval City, all the other tools were used to measure the engagement, the motivation and the collaboration of the students. All tests and the interview were conducted five days after the accomplishment of the experiment. In the following section, some of the most interesting results are summarized.

\section{RESEARCH RESULTS}

\section{A. Learning Outcomes}

According to results of multiple choice learning tests (Table II), all students except student S1 have answered only one or two questions incorrectly. The S1 has six wrong answers. The rate of correct answers is rather high since they concerned memorization of facts five days after the experiment and the participants did not know this information before.

Most of the wrong answers concerned a) historical places that are not so famous and there were few possibilities for the students to have heard anything about them before playing the game or b) answers "hidden" in long conversations with visual characters. This revealed that the students lost their attention while they were in long conversations with visual characters. Moreover, the researchers realized by the questionnaires and video recordings that the students had great desire to see the end of the story and catch the ghost, which led them to pass careless-

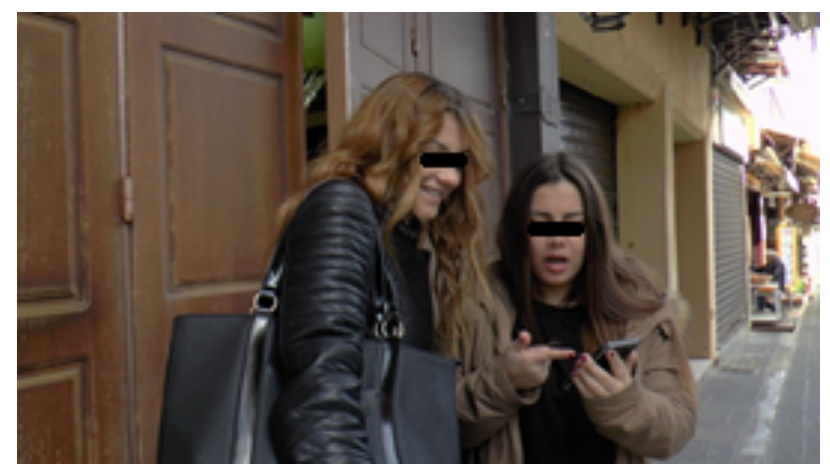

Figure 2. Participants while playing the game

TABLE II.

LEARNING OUTCOME OF RHODESK-NIGHTS

\begin{tabular}{|c|c|}
\hline Student & Right Answers / All Answers \\
\hline S1 & $9 / 15$ \\
\hline S2 & $14 / 15$ \\
\hline S3 & $14 / 15$ \\
\hline S4 & $13 / 15$ \\
\hline S5 & $13 / 15$ \\
\hline S6 & $13 / 15$ \\
\hline S7 & $14 / 15$ \\
\hline
\end{tabular}


ly such long dialogues. For example, one student forced her teammate to give a fast answer to a question which she did not read at all in order to move to next challenge. Furthermore almost all students answered with number six or seven to the questions "How much do you like the sto$r y$ " and "Do you wanted to find the ghost or just played for entertainment", which shows that they all liked the story and they wanted to catch the ghost, which is a fact that reinforces our belief that the great desire of the players to reach at the end of the plot, led them to misunderstandings. Finally, all the students declared that they not only did they improve their knowledge about Medieval History of Rhodes but they also expected the game to include more historical information.

\section{B. Engagement-Motivation-Collaboration Level}

First of all, for most of the students except one, this was their first time playing an augmented reality game. Researchers believe that this fact plays a major role in the engagement and motivation because new technologies usually motivate and engage young people and especially students [35], [4]. As revealed from the questionnaires, the interview and the recording, the students seemed to like the game and the narration motivated them. As mentioned before, all students enjoyed the story because all of them wanted to win and catch the ghost. Moreover, they believed that the story was neither long nor short and so they didn't get bored or tired while they were walking in the streets of Medieval City. The students noted as an important factor for engagement and authenticity the use of the medieval city as the scene of the story. This reveals an advantage of the location based MAR games. The duration of the game playing varied between an hour and an hour and a half. One student said in the interview that she was embarrassed when the game finished and wanted more. They also believed that the historical information did not distract their attention from the story. In some cases the cognitive load of a game is too much which results to lack of balance with story plot and distracts payer attention from final purpose [40].In the question "if they will remove something from the game" all the participants answer "Nothing" and all of them would suggest the game to their friends. Finally, all of them answered that they would like to play again either Rhodes K-Nights or other Augmented Reality game which reveals that the students develop positive attitude about AR. According to questionnaires, all participants collaborated with their teammates except from the student who played it alone. The answers showed that the main reason of collaboration was decision making about the game, e.g. to select the correct answer to a question or to select a virtual character to talk with. However, the recordings reveal that the players were also collaborating intensively in order to be orientated in the Medieval City, although they didn't mention it in the questionnaires. This happened because maybe they didn't realize that the correct orientation was part of the game and part of location-based Augmented Reality applications in general. All the participants believed the collaboration was necessary and they wouldn't prefer having played the game by themselves. The collaboration was face to face in front the device, students asked for a multi user version of the game so that they could collaborate through their devices. Finally, most of them (five students) wanted the game to be competitive and to play against the other team.
One basic limitation of the current version of the game is that it does not offer computer supported collaboration. In the future versions, the jigsaw collaboration scheme will be employed. Jigsaw collaboration is expected to reinforce role playing, which in turn as mentioned previously, encourages the collaboration resulting in increased engagement of the players and authenticity of the experience. Another direction for future development is the design of competition with opponents (e.g. including roles that support the ghost) which may make the game more challenging. Another limitation is the incomplete guidance instructions at some places of the Medieval City which resulted to meaningless wandering in the streets by the players for some time. Finally, the lack of open WiFi availability in the Medieval City makes possible the play of the game only by users with devices which support $3 \mathrm{G} / 4 \mathrm{G}$ access to the internet.

The design of "Rhodes K-nights" could fit in school field trips or afterschool programs. The content of the game could serve students (age 12+), citizens and visitors who are interested in the local history of Rhodes or they just want to participate in an entertaining experience. Thousands of tourists visit the island every year. The "Rhodes K-nights" prototype has been developed in order to serve as an example for the mystery narration genre. It will be used for the training of learning designers in ISMAR applications design as well as a test bed for field experiments about ISMAR effectiveness for learning. The user friendly interface of ARIS may help teachers/designers to overcome the technological skills obstacles allowing them to participate in further extension of the game.

\section{CONCLUSIONS AND Future Work}

Interactive storytelling constitutes a new genre of literature which promises considerable learning effectiveness while sets new research questions. In parallel, MAR applications development is maturing in terms of cost and technological capabilities required, since the corresponding devices and the application development tools are getting cheaper and user friendly. This situation makes the development of ISMAR applications for learning and entertainment both feasible and attractive. ISMAR applications enable the offering of unprecedented [8] experiences with significant potential impact to learning and economy. Interactive Storytelling authoring meets a new area because of the location and context awareness of MAR technology. MAR as a new IS medium raises new opportunities, as well as challenges, for the story authors and the learning designers. The review of the available MAR development technologies shows that user friendly authoring tools are already available, accompanied with lively developers communities of practice. These tools, smoothing several obstacles, could enable a new generation of ISMAR applications to appear from the collaboration of learning designers, writers and subject matter experts. The theoretical analysis and the research review concerning the relation of ISMAR technology with learning, support the need for further study of best practices, the recognition of successful design patterns and the development of a rapid prototyping methodology in order to educate the learning designers, researchers, writers etc. how to develop ISMAR applications and thus to facilitate their experimental pedagogical research. 
The critical review of existing examples of MAR Serious Games shows that the mystery narrative genre, based on science fiction themes in combination with the collaborative inquiry approach, outlines a successful pattern for the design of ISMAR learning applications. This design pattern was used as the basis for the production of the experimental ISMAR Serious Game "Rhodes K-nights". The game will be used for learning designers training in rapid prototyping methodology. "Rhodes K-nights" future versions will also be evaluated experimentally with larger groups of players. The authors will also continue the current work in the direction of the professional development of learning designers, writers, researchers and educators, as well as to the exploration of the narrative genre impact to the efficiency of the ISMAR learning applications. Future work will include also the finding and/or development of exemplary ISMAR learning applications for each narrative genre in order to outline and evaluate the corresponding design patterns.

\section{REFERENCES}

[1] J. Bruner, Actual minds, possible worlds. Cambridge, MA: Harvard University Press, 1986.

[2] J. Bruner, "The Narrative Construction of Reality," Critical Inquiry, 1991, 18(1), 1-21. http://dx.doi.org/10.1086/448619

[3] M. Bower, C. Howe, N. McCredie, A. Robinson, and D. Grover. "Augmented Reality in education - cases, places and potentials," EMI. Educ. Media Int., 2014, 51(1), pp. 1-15. http://dx.doi.org/ 10.1080/09523987.2014.889400

[4] T. M. Connolly, E. A. Boyle, E. MacArthur, T. Hainey, and J. M. Boyle, "A systematic literature review of empirical evidence on computer games and serious games," Computers and Education, 2012, 59(2), 661-686. http://dx.doi.org/10.1016/j.compedu.2012. $\underline{03.004}$

[5] C. Crawford, Chris Crawford on interactive Storytelling.United States of America: New Riders publishing, 2013.

[6] M. Dunleavy, C. Dede, and R. Mitchell, "Affordances and limitations of immersive participatory augmented reality simulations for teaching and learning," Journal of Science Education and Technology, 2009, 18, 7-22. http://dx.doi.org/10.1007//10956-0089119-1

[7] R. Earnshaw, "From E-Learning to M-Learning - the use of Mixed Reality Games as a new Educational Paradigm," International Journal of Interactive Mobile Technologies (iJIM), 2011, 5(2). http://dx.doi.org/10.3991/ijim.v5i2.1463

[8] Edutainment (Conference). Edutainment technologies: educational games and virtual reality/augmented reality applications: In M. Chang, (Ed.) proceedings of 6th International Conference on Elearning and Games, EdutainmentSeptember2011, Taipei, Taiwan, Heidelberg: Springer, 2011. http://dx.doi.org/10.1007/978-3-64223456-9

[9] K. Egan, "Narrative and learning: A voyage of implications," Linguistics and Education, 1993, 5(2), 119-126. http://dx.doi.org/10.1016/0898-5898(93)90028-9

[10] W. R. Foshay, and F. Preese, "Do we need authoring systems? A commercial perspective, "Technology, Instruction, Cognition \& Learning (TICL), 2005, 2(3), pp. 249-260.

[11] J. P. Gee, What video games have to teach us about learning and literacy. Palgrave Macmillan, New York, 2003.

[12] P. Harrigan, and N. Wardrip-Fruin, Second person: role-playing and story in games and playable media (1. MIT Press paperback ed). Cambridge, Mass.: MIT Press, 2010.

[13] C.L. Holden. and J.M. Sykes, "Leveraging mobile games for place-based language learning," International Journal of GameBased Learning, 2011, 1, pp. 1-18. http://dx.doi.org/10.4018/ ijgbl.2011040101

[14] C. Holden, "The Local Games Lab ABQ: Homegrown Augmented Reality," TechTrends, 2014, 58(1), 42-48. http://dx.doi.org/10. 1007/s11528-013-0719-0
[15] J. Huizenga, W. Admiraal, S. Akkerman, and G. ten Dam, "Mobile game-based learning in secondary education: engagement, motivation and learning in a mobile city game," Journal of Computer Assisted Learning, 2009, 25(4), 332-344. http://dx.doi.org/10.1111/j.1365-2729.2009.00316.x

[16] L. Johnson, A. Levine, R. Smith, and S. Stone, The 2010 Horizon Report. Austin, Texas: The New Media Consortium, 2010.

[17] K. Egan, "Teaching as Story-telling: A Non-mechanistic Approach to Planning Teaching", 1985, 17:4, 397-406, http://dx.doi.org/10.1080/0022027850170405

[18] E. Klopfer, Augmented learning: research and design of mobile educational games. Cambridge, Mass: MIT Press, 2008. http://dx.doi.org/10.7551/mitpress/9780262113151.001.0001

[19] Ö., Korkmaz, "New Trends on Mobile Learning in The Light of Recent Studies," Participatory Educational Research, 2014, 2(1), 1-10, Available online at: http://www.partedres.com.

[20] J. Lave, and E. Wenger, Situated learning: Legitimate peripheral participation. Cambridge: Cambridge University Press, 1991. http://dx.doi.org/10.1017/CBO9780511815355

[21] J. Martin, S. Dikkers, K. Squire, and D. Gagnon, "Participatory scaling through augmented reality learning through local games," TechTrends, 2014, 58 (1), pp. 35-41. http://dx.doi.org/10.1007/ s11528-013-0718-1

[22] M. Mateas, and A. Stern, "Structuring Content in the Facade Interactive Drama Architecture," In Proceedings of Artificial Intelligence and Interactive Digital Entertainment (AIIDE 2005), Marina del Rey, June, 2005.

[23] A. Mitchell and T. L. Chuah, "Telling stories on the go: Lessons from a mobile thematic storytelling system," In: Proc. ICIDS 2013, Springer Verlag, 2013, 83-94. http://dx.doi.org/10.1007/ 978-3-319-02756-2 10

[24] A. Molnar, D. Farrell, and P. Kostova, "Who poisened Hugh? The STAR framework: Integrating learning objectives with storytelling,” In: Proc. ICIDS 2012, San Sebastián, Spain, Nov. 12-15, 2012, Springer Verlag, 2012, 60-71.

[25] E. Rosenbaum, E. Klopfer, and J. Perry, "On location learning: authentic applied science with networked augmented realities" Journal of Science Education and Technology, 2007, 16(1), pp. 31-45. http://dx.doi.org/10.1007/s10956-006-9036-0

[26] K.D. Squire and M. Jan, "Mad city mystery: developing scientific argumentation skills with a place-based augmented reality game on handheld computers," Journal of Science Education and Technology, 2007, 16(1), pp. 5-29. http://dx.doi.org/10.1007/s10956006-9037-z

[27] A. Stern, "Embracing the combinatorial explosion: A brief prescription for interactive story R\&D," In: ICIDS 2008, Erfurt, Germany, Nov. 26-29, 2008, Springer Verlag, 1-5. http://dx.doi.org/10.1007/978-3-540-89454-4 1

[28] N. Wardrip-Fruin, and P. Harrigan, "Second person: role-playing and story in games and playable media". Cambridge, Mass: MIT Press, 2007.

[29] R. Luce-Kapler, and T. Dobson, "In search of a story: Reading and writing e-literature" Reading Online, 2005, 8(6).

[30] F. Garzotto, P. Paolini, and A. Sabiescu. "Interactive storytelling for children," In Proceedings of the 9th International Conference on Interaction Design and Children (Barcelona, Spain, June 9-12, 2010), IDC '10. ACM, New York, NY, USA, 356-359. DOI=http://doi.acm.org/10.1145/1810543.1810613

[31] R. Bromme, and E. Stahl, "Writing and learning: Hypertext as a renewal of an old and close relationship - Introduction and overview," In R. Bromme \& E. Stahl (Eds.), Writing hypertext and learning: Conceptual and empirical approaches. Kidlington, Oxford: Elsevier Science Ltd,2002.

[32] G. P. Landow, "Hypertext 3.0: Critical Theory and New Media in an Era of Globalization. Baltimore," ML: Johns Hopkins University Press, 2006

[33] H.-K. Wu, S. W.-Y. Lee, H.-Y. Chang, and J.-C. Liang "Current status, opportunities and challenges of augmented reality in education", Computers \& Education, 2013, 62, 41-49 http://dx.doi.org/10.1016/j.compedu.2012.10.024

[34] A.N Applebee. The child's concept of story. Chicago: University of Chicago Press, 1978 
PAPER

RAPID PRototyping of INTERACTIVE StORYTELling AND MOBILE AUGMENTED REALITy APPLICATIONS FOR...

[35] J. Gikas, and M. Grant."Mobile computing devices in higher education: Student perspectives on learning with cellphones, smartphones, and social media", Internet and Higher Education, 2013, 19, 18-26. http://dx.doi.org/10.1016/j.iheduc.2013.06.002

[36] J. Sandberg, M. Maris, and K. de Geus. "Mobile English learning: an evidence-based study with fifth graders", Computers \& Education, 2011, 57, 1334-1347 http://dx.doi.org/10.1016/j.comp edu.2011.01.015

[37] R.T. Azuma, "A survey of augmented reality" PresenceTeleoperators and Virtual Environments, 1997, 6 (4), 355-385 http://dx.doi.org/10.1162/pres.1997.6.4.355

[38] P. Milgram, H. Takemura, A. Utsumi, and F. Kishino. "Augmented reality: a class of displays on the reality-virtuality continuum", Proceedings the SPIE: Telemanipulator and Telepresence Technologies, 2351, 1994, 282-292 http://dx.doi.org/10.1117/ $\underline{12.197321}$
[39] P. Dillenbourg, "Over-scripting CSCL: The risks of blending collaborative learning with instructional design." Three worlds of CSCL. Can we support CSCL?,2002, 61-91.

[40] D. Squire, and J. Preece, "Usability and learning: evaluating the potential of educational software", Computer Education, 1996, 27(1), 15-22 http://dx.doi.org/10.1016/0360-1315(96)00010-3

\section{AUTHORS}

D. Markouzis is Phd Student in University of the Aegean/LTEE Lab, Rhodes, 85132, Greece (e-mail: markouzis@aegean.gr)

G. Fessakis is with University of the Aegean/LTEE Lab, Rhodes, 85132, Greece (e-mail: gfesakis@aegean.gr)

This article is an extended and modified version of a paper presented at the International Conference on Interactive Collaborative Learning (ICL2015), held 20-24 December 2015, in Florence, Italy. Submitted 14 February 2016. Published as resubmitted by the authors 16 April 2016. 